Revista Destaques Acadêmicos, Lajeado, v. 10, n. 4, 2018. ISSN 2176-3070

DOI: http://dx.doi.org/10.22410/issn.2176-3070.v10i4a2018.2034

http://www.univates.br/revistas

\title{
USANDO AS METODOLOGIAS ATIVAS NA EDUCAÇÃO PROFISSIONAL: IDENTIFICAÇÃO, COMPREENSÃO E ANÁLISE NAS PERCEPÇÕES DOS ESTUDANTES
}

\author{
Flávia Capalonga ${ }^{1}$, Maria Claudete Schorr Wildner ${ }^{2}$
}

\begin{abstract}
Resumo: O presente artigo aborda o conceito de metodologias ativas e as principais transformações que estão ocorrendo nos processos de ensino aprendizagem. Entendemse essas como novas práticas pedagógicas que consistem em colocar o aluno como protagonista na construção da aprendizagem, diferenciando do método tradicional. Por conta disso, foi realizado um estudo com estudantes de diferentes cursos técnicos profissionalizantes de uma instituição de ensino do Vale do Taquari - Rio Grande do Sul, a fim de ter melhor clareza sobre suas percepções diante das metodologias ativas utilizadas por seus docentes em sala de aula e sobre as possíveis capacidades que são por eles desenvolvidas na construção do conhecimento. Pelos resultados obtidos, conclui-se que usar práticas pedagógicas inovadoras, bem como usufruí-las da melhor maneira, os estudantes as identificam e as consideram benéficas para o seu desenvolvimento estudantil e profissional. Além disso, acredita-se que quando docentes e discentes atuam juntos, os processos de aprendizagem e de ensino são mais eficazes.
\end{abstract}

Palavras-chave: Metodologias Ativas. Educação Profissional. Estudantes.

\section{INTRODUÇÃO}

Ao longo dos últimos anos ocorreram grandes mudanças sociais, culturais e tecnológicas. A educação faz parte desse contexto e vem sofrendo com a falta de interesse dos alunos pela escola e pela maneira com que os professores conduzem suas aulas (ROCHA e LEMOS, 2014). Diante disso, muito se discute sobre as transformações nas formas de aprendizagem e como os avanços tecnológicos possibilitam o uso de diversas metodologias ativas na formação do estudante.

1 Tecnóloga em Radiologia. Pós-Graduada no Curso de Pós-Graduação Lato Sensu Especialização em Docência na Educação Profissional da Univates.

2 Docente da Universidade do Vale do Taquari - Univates. 
Entende-se que metodologias ativas são formas de desenvolver os processos da aprendizagem, e estas são utilizadas pelos professores a fim de conduzir a formação crítica dos futuros profissionais, favorecendo mais autonomia ao estudante, despertando a curiosidade e estimulando tomadas de decisões (BORGES e ALENCAR, 2014). Para Berbel (2011), as metodologias ativas além de desenvolver o processo de aprender, utilizam experiências reais ou simuladas, visando condições de solucionar com êxito os desafios advindos das atividades essenciais da prática social em diferentes contextos.

Considera-se que a educação é contínua, desenvolve e prepara o estudante para a vida profissional. Por isso, há a necessidade da aproximação com a realidade e a relação educação - trabalho é essencial para se obter um crescimento pessoal e profissional.

Diante a essas mudanças, as escolas estão modernizando-se, passando por um processo de aperfeiçoamento, a fim de atender as práticas que estimulam a criatividade, inovação e capacitação dos individuo para a aprendizagem (CALDWELL e SPINKS, 1998).

A educação profissionalizante já faz parte desse grupo de escolas, sendo uma das opções de ensino que tem como objetivos formar alunos com competências teóricas e práticas, além de promover um profissional proativo, autônomo, criativo, responsável e de qualidade, a fim de conseguir desenvolver e resolver as diversas situações que lhe aparecerão no dia-a-dia.

Neste artigo discute-se sobre a identificação, compreensão e análise dos benefícios da utilização das metodologias ativas na educação profissional, a partir da visão dos estudantes. O objetivo do presente trabalho é perceber e entender como o aluno identifica, compreende e analisa o uso das metodologias ativas usadas pelos seus professores e observar alguns benefícios pontuados, advindos da utilização das mesmas.

O presente trabalho foi desenvolvido, por meio de pesquisa realizada com estudantes de um centro de educação profissional de uma Universidade no Vale do Taquari, no estado do Rio Grande do Sul, visto que, na prática docente, percebe-se uma carência por parte dos estudantes na identificação e entendimento da importância e relevância que as diferentes técnicas pedagógicas têm na obtenção do conhecimento e destreza no âmbito profissional.

\section{METODOLOGIAS ATIVAS: TRANSFORMAÇÃO}

Borges e Alencar (2014) comentam que os processos de ensino e aprendizagem sempre estiveram presentes no relacionamento entre os humanos, seja de forma direta ou indireta. Uma das principais questões relacionadas a isso são as metodologias ativas utilizadas em sala de aula, e a necessidade de constatar a eficácia e eficiência das técnicas docentes nesses processos. 
Pavanelo e Lima (2017) relatam o quanto é necessário repensar os parâmetros educacionais a fim de modificar o trabalho e as atividades docentes. Essa renovação requer uma reorganização das teorias de ensino, um novo papel da instituição perante a sociedade, conquistando assim, uma nova postura docente. Destacam também, a inquietação dos alunos referente as mudanças relacionadas ao ensino-aprendizagem e a motivação dos mesmos quanto a inovação desses processos. E isso pode ser atenuado a partir da postura do professor e aluno em sala de aula.

Estabelece-se que a metodologia ativa está centrada no aluno, tornando-o protagonista do processo de aprendizagem, diferente do método tradicional, no qual o professor possuía o papel principal na transmissão de conhecimento (ARAUJO, 2015).

Essas transformações no processo de ensino aprendizagem devem acontecer com calma e a escolha da metodologia deve ser de forma consciente, pensada e preparada (BORGES e ALENCAR, 2014). Elas precisam acompanhar os objetivos pretendidos e dar início ao avanço dos processos mais complexos de reflexão, de integração cognitiva, de generalização e de reelaboração de novas práticas (MORÁN, 2015).

Berbel (2011, p. 28), destaca que "o professor deve adotar as perspectivas do aluno, deve escolher seus pensamentos, sentimentos e ações, sempre que manifestados, e apoiar o seu desenvolvimento motivacional e capacidade para autorregular-se". Acredita-se que as metodologias ativas despertam a curiosidade quando há a integração do aluno, e ao ser analisada e valorizada pelo professor, estimulam os sentimentos dos estudantes, deixando-os mais próximos dos estudos e melhorando suas capacidades de autonomia, e competência.

Borges e Alencar (2014, p. 210), confirmam isso enfatizando que "uma proposta construtiva para o ensino superior consiste em educar para a autonomia, através de metodologias inovadoras". Para que isso ocorra, alguns recursos podem ser utilizados, como pesquisas, além de promover os trabalhos em grupo, propiciando a participação dos alunos.

Na educação profissional, Silva (2015) destaca que o professor como o de outros níveis de ensino, precisa além de ter conhecimentos na área que atua, requer conhecer estratégias de ensino que possibilitem aos estudantes aprender e não apenas memorizar informações. Para o professor de nível técnico é primordial ter uma visão de mundo, de ser humano, de ciência e de educação compatível com as características de sua função.

Considera-se que na educação, o interessante não é fazer-se o uso de grandes recursos, mas desenvolver atitudes afetivas e comunicativas favoráveis e algumas táticas de negociação com os alunos a fim de facilitar as mudanças, estimulando a criatividade e confiança, transformando a sala de aula em uma 
comunidade de investigação correspondendo as necessidades dos estudantes, estabelecendo conexões com o cotidiano e com o inesperado (MORAN, 2013).

Diversas são as metodologias ativas que podem ser utilizadas dentro do espaço educacional, tendo em vista a necessidade de utilizar não apenas a sala de aula, mas também o tempo e espaço fora dela. As práticas que vêm ganhando destaque nesse contexto são as que aproximam os alunos da realidade, pois nesta perspectiva, o conhecimento é construído pela ação de agir sobre a mesma (MARIN, LIMA et al. 2010).

No estudo realizado por Borges e Alencar (2014), destaca-se a percepção de diversos autores sobre o papel e posição do docente, pois consideram que os recursos didáticos são os responsáveis pela formação crítica-reflexiva do estudante. Eles expõem a teoria de Candau (1991) a qual refere-se ao educador como todo ser que atua na prática transformadora, cria condições de habilidades individuais ou de grupos, utilizando recursos didáticos que proporcionam o aprendizado de forma ativa e motivadora. Aponta também a percepção de Freire (2007) quando expõe que o desempenho docente é o apoio de uma boa formação, contribuindo para a construção de uma sociedade pensante.

Entretanto, independente da metodologia utilizada pelo docente, é fundamental que o aluno faça o uso de suas ações mentais de pensar, raciocinar, observar, refletir, entender, combinar, dentre outras que formam a inteligência, conforme mencionado por Barbosa e Moura (2013).

Diante ao exposto, é possível afirmar que utilizar metodologias ativas requer uma mudança de comportamento docente e estudantil. Pode-se observar no estudo realizado por Marin, Lima et al. (2010) a apresentação de algumas fragilidades e fortalezas citadas pelos estudantes após vivenciarem o uso das metodologias ativas. Segundo as narrativas dos mesmos o estudo é constante, a curiosidade, independência, aproximação com o ensino e a realidade, responsabilidade, interação e desenvolvimento de habilidades são as principais fortalezas pontuadas. Destacam como fragilidades a insegurança, o esforço constante, amadurecimento e organização. E citam a importância da postura docente como condutora das atividades para que haja um aprendizado eficaz.

Outro ponto que merece destaque e de grande importância nos processos de aprendizagem é a relação professor-aluno, pois essa ligação gera comprometimento com a construção do conhecimento. Quanto a isso Masetto (2001, p.22) destaca:

É importante que o professor desenvolva uma atitude de parceria e corresponsabilidade com os alunos, que planejam o curso junto, usando técnicas em sala de aula que facilitem a participação e considerando os alunos como adultos que podem corresponsabilizar por seu período de formação profissional. 
Em vista disso, estima-se por uma relação de respeito e confiança, para que além de desenvolver a aprendizagem, proporcione a formação do ser humano. Dessa forma, Paulo Freire (2016, p. 21) ressalta que o diálogo é fundamental para estabelecer boas relações educador - educando, considera que ensinar é trocar informações e que ambos alteram-se em suas funções. "O educando aprende e, ao mesmo tempo educa, o educador, da mesma forma, ensina e aprende. Portanto, não há educação sem diálogo".

\section{PROCEDIMENTOS METODOLÓGICOS}

Diante das diversas mudanças que estão ocorrendo no ambiente educacional com o avanço das tecnologias e as possibilidades de novas práticas pedagógicas, a instituição participante do estudo percebeu que poderia haver uma mudança nos processos ensino e aprendizagem tanto na modalidade do estudo profissionalizante quanto na graduação. Por isso, iniciou-se uma transformação nos métodos educacionais, optando para a utilização das metodologias ativas como novas formas de aprimorar e qualificar o conhecimento.

Em razão disso e considerando o curso profissionalizante como referência, este artigo apresenta um estudo com estudantes do Centro de Educação Profissional (CEP) de uma instituição de ensino do Vale do Taquari - Rio Grande do Sul.

A metodologia aplicada e a obtenção dos resultados caracterizam uma pesquisa quantitativa. Fonseca (apud GERHARDT E SILVEIRA, 2009, p.33), destaca que:

A pesquisa quantitativa se centra na objetividade. Influenciada pelo positivismo, considera que a realidade só pode ser compreendida com base na análise de dados brutos, recolhidos com o auxílio de instrumentos padronizados e neutros. A pesquisa quantitativa recorre à linguagem matemática para descrever as causas de um fenômeno, as relações entre variáveis, etc.

Inicialmente entrou-se em contato com o Centro Educacional Profissionalizante (CEP) da instituição via e-mail solicitando a liberação para realizar o estudo com as turmas que já concluíram pelo menos dois semestres dos cursos técnicos até o primeiro semestre do ano 2018, período este que foi desempenhado o presente trabalho. A partir desse prévio contato, a pesquisa foi realizada nas salas de aula, aplicando-se um questionário (Quadro 1) de forma impressa. $\mathrm{O}$ questionário foi utilizado de forma impressa a fim de ter maior efetividade na coleta dos dados e possibilitar as pesquisadoras um contato maior com os alunos ao explicar brevemente o conceito de metodologias ativas antes de aplicar o questionário, possibilitando também conversas e soluções de dúvidas enquanto os estudantes o realizavam. Participaram da pesquisa cem 
estudantes que cursam o terceiro, quarto e quinto semestres dos cursos técnicos de Administração, Automação, Eletroeletrônica, Radiologia e Transições Imobiliárias onde responderam as questões objetivas do Quadro 1, tendo como respostas as opções sim ou não.

Quadro 1: Questionário aplicado aos alunos

\begin{tabular}{|r|l|}
\hline Pergunta & Descrição \\
\hline 01. & $\begin{array}{l}\text { Nos últimos anos percebe-se uma mudança do comportamento docente } \\
\text { dentro da sala de aula. Faz-se uso de metodologias ativas, sendo elas, } \\
\text { novas práticas pedagógicas que apresenta o objetivo de integrar o } \\
\text { aluno às atividades educacionais, tornando-o mais ativo na busca do } \\
\text { conhecimento. Você percebe o uso das metodologias ativas por parte dos } \\
\text { seus docentes? } \\
\text { ( ) sim ( ) não }\end{array}$ \\
\hline 02. & $\begin{array}{l}\text { (Se você respondeu NÃO na questão anterior desconsiderar essa questão) } \\
\text { E quando usadas, você considera que a aula torna-se mais atrativa, } \\
\text { despertando sua curiosidade e seu interesse em aprender, quando } \\
\text { comparada a uma aula somente expositiva? } \\
\text { () sim ( ) não }\end{array}$ \\
\hline 03. & $\begin{array}{l}\text { Com as novas práticas pedagógicas, o professor tem o papel de instruir, } \\
\text { conduzir as atividades deixando o aluno como protagonista na busca do } \\
\text { conhecimento. Pelas práticas vivenciadas, você considera que isso quando } \\
\text { executado de forma correta, é benéfico para o seu desenvolvimento? } \\
\text { () sim ( ) não }\end{array}$ \\
\hline 04. & $\begin{array}{l}\text { Há diferentes técnicas que podem ser utilizadas pelos docentes a fim } \\
\text { de promover a integração e a aprendizagem. Quando utilizadas, você } \\
\text { percebe uma melhora na sua aprendizagem? } \\
\text { () sim ( ) não }\end{array}$ \\
\hline 05. & $\begin{array}{l}\text { Utilizar metodologias ativas requer um novo comportamento dentro e } \\
\text { fora da sala de aula, necessita do aluno organização, empenho e atitude, } \\
\text { você considera que essas características exigidas pelas novas práticas } \\
\text { pedagógicas são benéficas para o seu desempenho como aluno / } \\
\text { profissional? } \\
\text { ( ) sim ( ) não }\end{array}$ \\
\hline
\end{tabular}




\begin{tabular}{|r|l|}
\hline Pergunta & Descrição \\
\hline 06. & $\begin{array}{l}\text { Quando utilizadas metodologias ativas que o aproximam da realidade, } \\
\text { exemplificando possíveis situações ou problemas que podem ser } \\
\text { encontrados na sua futura profissão, você considera que estas são } \\
\text { importantes e que instigam suas capacidades de análise, reflexão, decisão } \\
\text { e atitude? } \\
\text { ( ) sim ( ) não }\end{array}$ \\
\hline 07. & $\begin{array}{l}\text { Colocar o aluno como protagonista nos processos de ensino aprendizagem } \\
\text { é o objetivo das metodologias ativas, tornando- o mais criativo, pensante, } \\
\text { crítico, autônomo e corresponsável pelo seu aprendizado, dentre as } \\
\text { metodologias utilizadas por seus docentes, você percebe isso como um } \\
\text { benefício para a sua vida estudantil e profissional? } \\
\text { ( ) sim ( ) não }\end{array}$ \\
\hline
\end{tabular}

Fonte: Dos autores (2018).

Os resultados obtidos foram tabulados, para posterior análise e comparação com as referências bibliográficas, além de observar novas suposições adquiridas por meio das respostas assinaladas pelos participantes. Tendo em vista melhores discussões e apreciação dos resultados.

\section{RESULTADOS E DISCUSSÕES}

Nesta seção serão apresentados os resultados adquiridos a partir da pesquisa realizada em sala de aula com estudantes de distintos cursos técnicos profissionalizantes de uma Instituição de Ensino do Vale do Taquari- Rio Grande do Sul.

A partir da análise dos dados obtidos, observa-se (Gráfico 1) que a maioria dos estudantes pesquisados identificam o uso das metodologias ativas por parte dos seus docentes em diferentes áreas de cursos técnicos. Rocha e Lemos (2014), ressalta que as metodologias ativas são novas formas de ensino - aprendizagem que agem na perspectiva de integrar teoria/prática, ensino/ serviço. 
Gráfico 1: Percentual de respostas da Questão 01

\section{Questão 01}

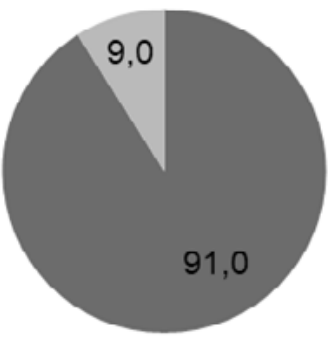

- $\%$ SIM

$\%$ NÃO

Fonte: Dos autores (2018).

Pavanelo e Lima (2017) relatam a necessidade de uma reflexão sobre os parâmetros educacionais, com o objetivo de modificar as atividades didáticas, sugere-se uma reorganização dos conteúdos trabalhados, redefinir teorias de ensino, uma nova postura da instituição perante a sociedade, consequentemente, uma nova postura docente. Analisando- se os resultados (Gráfico 2), entendese que implantar diferentes práticas pedagógicas que despertam a curiosidade e interesse do aluno em aprender.

Gráfico 2: Percentual de respostas da Questão $02^{3}$

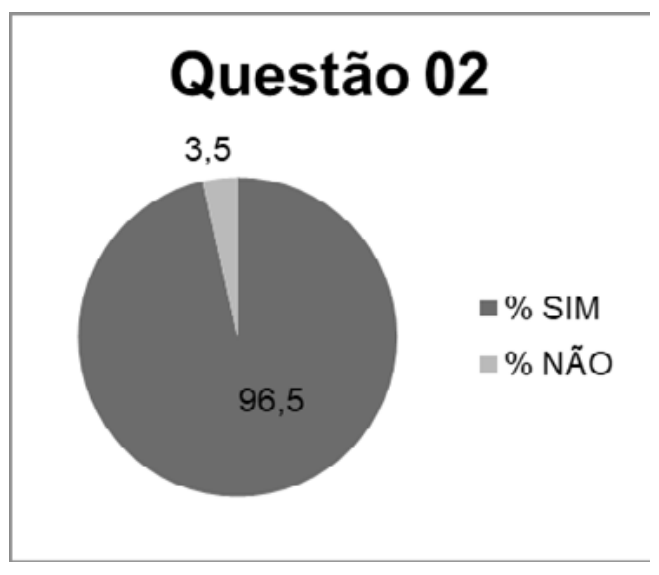

Fonte: Dos autores (2018).

3 Observação: Quinze estudantes não responderam esta questão. 
Para que ocorra uma aprendizagem ativa, o professor deixa de ser o transmissor de conhecimento e passa a atuar como orientador, supervisor e um facilitador nos processos de aprendizagem (Rocha e Lemos, 2014). Berbel (2011) complementa que o professor trabalha na perspectiva de que o aluno faça pesquisas, reflita e decida por ele mesmo, a fim de atingir os objetivos estabelecidos. Com isso, pode-se perceber (Gráfico 3) que é considerado benéfico na vida estudantil quando o docente deixa de ser a fonte transmissora e permite que o estudante atue como protagonista na busca do seu aprendizado.

Gráfico 3: Percentual de respostas da Questão 03

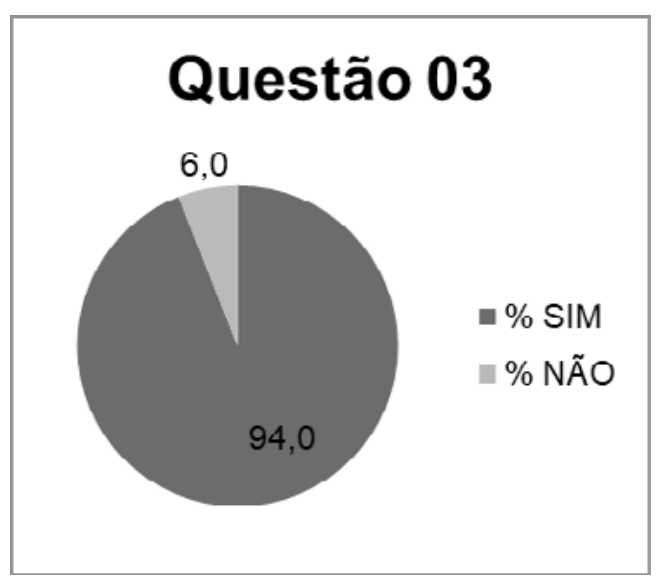

Fonte: Dos autores (2018).

Barbosa e Moura (2012) mencionam que a educação profissional requer uma aprendizagem significativa, com contextualização, com o apoio das tecnologias, que favoreça os recursos da inteligência e que proporcione habilidades de resolver problemas e conduzir projetos. Borges e Alencar (2014) comentam da importância de o professor utilizar técnicas que facilitam a participação dos alunos. A pesquisa mostra (Gráfico 4) que a aprendizagem ocorre quando há a integração dos estudantes nos processos de aprendizagem, seja pesquisando, estudando, ouvindo, falando, fazendo, ou seja, construindo o conhecimento. 
Gráfico 4: Percentual de respostas da Questão 04

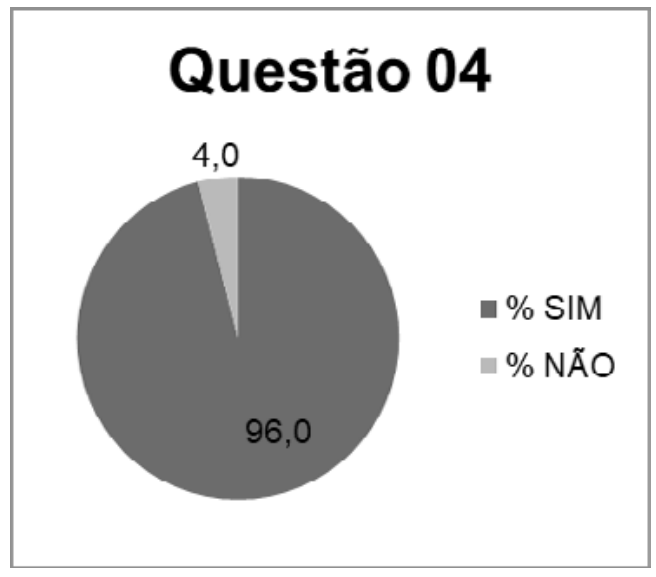

Fonte: Dos autores (2018).

$\mathrm{O}$ uso das metodologias ativas requer um novo comportamento docente e discente, e pelos dados obtidos (Gráfico 5), pode-se perceber que as características exigidas pelas novas práticas pedagógicas são benéficas para o desempenho aluno/profissional. Importante salientar que organização, estudo constante e atitude são os principais fatores para que a obtenção do conhecimento seja efetiva.

Gráfico 5: Percentual de respostas da Questão 05

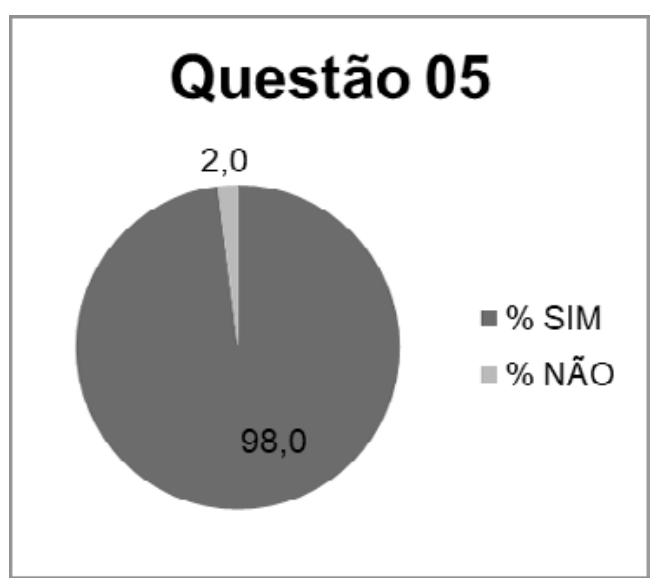

Fonte: Dos autores (2018).

Destaca-se também (Gráfico 6) que utilizar metodologias ativas que aproximam o aluno da realidade é benéfico para o seu desenvolvimento como estudante. Seguindo esta perspectiva, compreende-se que o conhecimento 
pode ser construído no agir sobre a realidade e que a ação crítica na realidade concede significado a aprendizagem (MARIN, LIMA et al. 2010).

Gráfico 6: Percentual de respostas da Questão 06

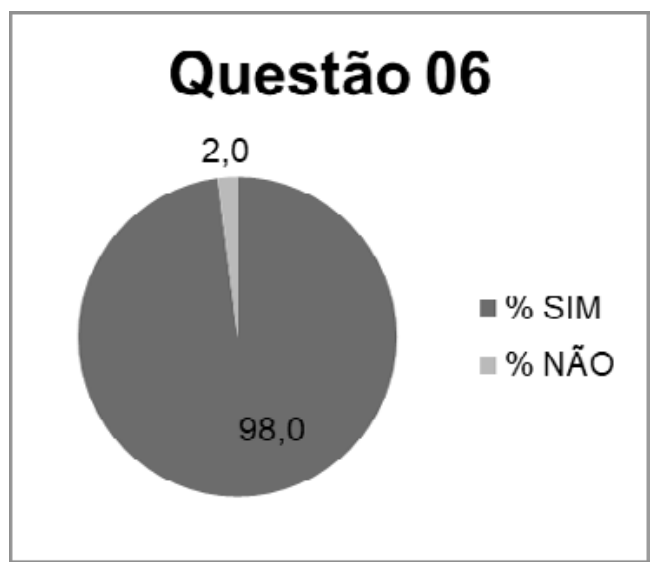

Fonte: Dos autores (2018).

A crescente complexidade dos diversos ramos profissionais requer diversas capacidades de desenvolvimento humano, ou seja, ações de pensar, sentir e agir de modo cada vez mais amplo e faz parte da escola contribuir para que isso ocorra (BERBEL, 2011). Por conta disso, escolas profissionalizantes fazem o uso de metodologias ativas, as quais buscam a motivação autônoma e o estímulo a curiosidade do estudante, deixando-os como os principais responsáveis pelos processos de aprendizagem favorecendo o desenvolvimento de competências (ROCHA E LEMOS, 2014). Observa-se (Gráfico 7) que os estudantes consideram que aperfeiçoar suas capacidades de pensar, agir e ser responsável pelo mesmo são relevantes para a vida estudantil e profissional. 
Gráfico 7: Percentual de respostas da Questão 07

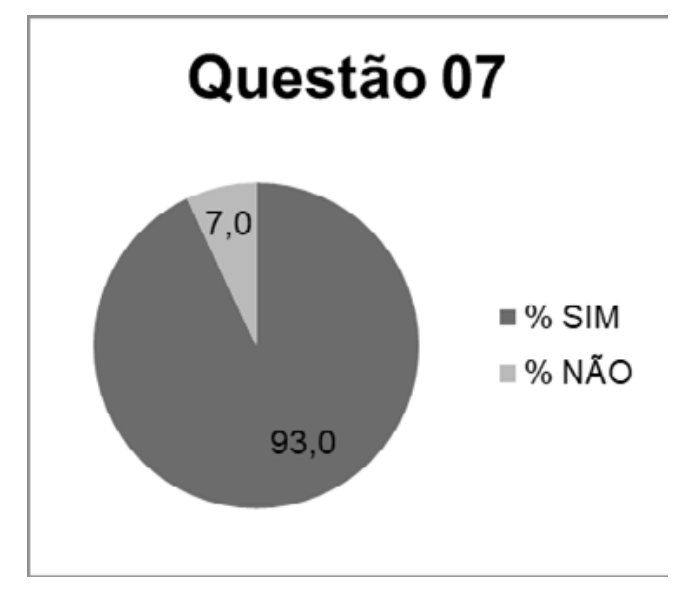

Fonte: Dos autores (2018).

\section{CONCLUSÃO}

Pelo estudo realizado, verifica-se que fazer o uso de diferentes metodologias ativas é importante e trazem benefícios para os estudantes nas mais diversas áreas. Destaca-se que a escola profissionalizante tem um papel fundamental e transformador no desenvolvimento das capacidades do futuro profissional e na construção do seu conhecimento, como também capacitá-los a refletir e analisar criticamente a sociedade de que fazem parte, tornando-os cidadãos pensantes.

Conclui-se então, que os estudantes identificam e valorizam o uso de novas práticas pedagógicas. E que as mesmas, quando bem aplicadas instiga o estudante na busca pelo aprender, tornando-o corresponsável na obtenção do conhecimento, desenvolvendo qualidades de pensar, analisar, criticar e agir, além de torná-lo mais responsável e qualificado. Ainda, acredita-se que quando docentes no papel de facilitadores e discentes como realizadores, comprometidos com suas atribuições, juntos fazem com que os processos de aprendizagem sejam mais eficazes.

\section{REFERÊNCIAS}

ARAUJO, José Carlos Souza. Fundamentos da Metodologia Ativa (1890-1931). In $37^{a}$ Reunião Nacional da ANPEd - 04 a 08 de outubro de 2015, UFSC - Florianópolis. Disponível em: <http://www.anped.org.br/sites/default/files/trabalho-gt02-4216. pdf $>$. Acesso em 20 dez. 2017.

BARBOSA, Eduardo Fernandes; MOURA, Dácio Guimarães. Metodologias Ativas de Aprendizagem Na Educação Profissional e Tecnológica. In B. Tec. Senac, Rio de 
Janeiro, v. 39, n.2, p.48-67, maio/ago. 2013. Disponível em: <http:/ /www.bts.senac. br/index.php/bts/article/view/349/333>. Acesso em 20 dez. 2017.

BERBEL, Neusi Aparecida Navas. As metodologias ativas e a promoção da autonomia de estudantes. In Semina: Ciências Sociais e Humanas, Londrina, v. 32, n. 1, p. 25-40, jan. /jun. 2011. Disponível em: <http:/ /www.uel.br/revistas/uel/index. php/seminasoc/article/view/10326/10999>. Acesso em 20 dez. 2017.

BORGES, Tiago S.; ALENCAR, Gidélia. Metodologias ativas na promoção da formação crítica do estudante: o uso das metodologias ativas como recurso didático na formação crítica do estudante do ensino superior. In Cairu em Revista. Jul/ Ago 2014, Ano 03, n 04, p. 1 19-143, ISSN 22377719. Disponível em: <http:/ / www.cairu.br/revista/arquivos/artigos/2014_2/08\%20METODOLOGIAS\%20 ATIVAS $\% 20 \mathrm{NA} \% 20$ PROMOCAO $\% 20 \mathrm{DA} \% 20 \mathrm{FORMACAO} \% 20 \mathrm{CRITICA} \% 20 \mathrm{DO} \% 20$ ESTUDANTE.pdf > . Acesso em 28 dez. 2017

CALDWELL, B. J.; SPINKS, J. M. Beyond the self-managing school.London: Falmer Press, 1998.FREIRE, Paulo. Desafios ao educador contemporâneo: perspectivas de Paulo Freire sobre a ação pedagógica de professores. Curitiba. Intersaberes, 2016. E-book. Disponível em: <http://univates.bv3.digitalpages.com.br/users/ publications/9788544303696>.

FONSECA, J. J. S. Metodologia da pesquisa científica. Fortaleza: UEC, 2002. Apostila.

GERHARDT, Tatiana Engel, SILVEIRA; Denise Tolfo. Métodos de Pesquisa.

Disponível em: <:/ / www.ufrgs.br/cursopgdr/downloadsSerie/derad005.pdf>. Acesso em 22 jan. 2018.

MARIN, Maria José Sanches; LIMA, Edna Flor Guimarães; et al. Aspectos da Fortalezas e Fragilidades no Uso das Metodologias Ativas de Aprendizagem. In Revista Brasileira de Educação Médica. SP, 2010. Disponível em: <http:/ / www.scielo. br/pdf/rbem/v34n1/a03v34n1.pdf>. Acesso em 22 dez. 2017.

MASETTO, M. A aula na universidade. In: VIII ENDIPE, Anais. Florianópolis, 1996,v.2, p.323-330.

MORÁN, José. Mudando a educação com metodologias ativas. In Coleção Mídias Contemporâneas. Convergências Midiáticas, Educação e Cidadania: aproximações jovens. Vol. II Carlos Alberto de Souza e Ofelia Elisa Torres Morales (orgs.). PG: Foca Foto-PROEX/UEPG, 2015. Disponível em:<http:/ / www2.eca.usp.br/moran/ wpcontent/uploads/2013/12/mudando_moran.pdf>. Acesso em 22 dez. 2017.

MORAN, José Manuel. A educação que desejamos: novos desafios de como chegar lá. Campinas, São Paulo: Papirus 2013.E-book. Disponível em: <http:/ / univates.bv3. digitalpages.com.br/users/publications/9788530810894>.

PAVANELO, Elisangela; LIMA, Renan. Sala de Aula Invertida: A Análise De Uma Experiência Na Disciplina de Cálculo I. In Bolema, Rio Claro (SP) v.31, n.58, p.739- 
759, Agosto/2017. Disponível em: <http://www.scielo.br/pdf/bolema/v31n58/0103636X-bolema-31-58-0739.pdf>. Acesso em: 20 dez. 2017.

ROCHA, Henrique Martins; LEMOS, Waschington de Macedo. Metodologias Ativas: Do que estamos falando? Base conceitual e Relato de Pesquisa em Andamento. In IX SIMPED - Simpósio Pedagógico e Pesquisas em Educação, 2014/2. Disponível em: <https://www.aedb.br/wp-content/uploads/2015/05/41321569.pdf>. Acesso em: 20 dez. 2017.

SILVA, Regina Nogueira da.A importância da didática no ensino superior, 2015 disponível em<http://www.ice.edu.br/TNX/storage/webdisco/2011/11/10/ outros/75a110bfebd8a8895 4e5f511ca9bdf8c.pdf> . Acesso em 18 de janeiro de 2018. 